\title{
Association between Socioeconomic Status and 30-Day and One-Year All-Cause Mortality after Surgery in South Korea
}

\author{
Tak Kyu Oh, Kooknam Kim, Sang-Hwan Do, Jung-Won Hwang and Young-Tae Jeon * \\ Department of Anesthesiology and Pain Medicine, Seoul National University Bundang Hospital, 166, Gumi-ro, \\ Bundang-gu, Seongnam 463-707, Korea; airohtak@hotmail.com (T.K.O.); 54271@snubh.org (K.K.); \\ shdo@snu.ac.kr (S.-H.D.); jungwon@snubh.org (J.-W.H.) \\ * Correspondence: ytjeon@snubh.org; Tel.: +82-31-787-7499; Fax: +82-31-787-4063
}

Received: 29 January 2018; Accepted: 8 March 2018; Published: 10 March 2018

\begin{abstract}
Preoperative socioeconomic status (SES) is associated with outcomes after surgery, although the effect on mortality may vary according to region. This retrospective study evaluated patients who underwent elective surgery at a tertiary hospital from 2011 to 2015 in South Korea. Preoperative SES factors (education, religion, marital status, and occupation) were evaluated for their association with 30-day and one-year all-cause mortality. The final analysis included 80,969 patients who were $\geq 30$ years old, with 30 -day mortality detected in 339 cases $(0.4 \%)$ and one-year mortality detected in 2687 cases (3.3\%). As compared to never-married patients, those who were married or cohabitating (odds ratio (OR): $0.678,95 \%$ confidence interval (CI): 0.462-0.995) and those divorced or separated (OR: $0.573,95 \%$ CI: 0.359-0.917) had a lower risk of 30-day mortality after surgery. Similarly, the risk of one-year mortality after surgery was lower among married or cohabitating patients (OR: 0.857, 95\% CI: 0.746-0.983) than it was for those who had never married. Moreover, as compared to nonreligious patients, Protestant patients had a decreased risk of 30-day mortality after surgery (OR: 0.642, 95\% CI: $0.476-0.866$ ). The present study revealed that marital status and religious affiliation are associated with risk of 30-day and one-year all-cause mortality after surgery.
\end{abstract}

Keywords: mortality; marriage; general surgery

\section{Introduction}

Socioeconomic status (SES) encompasses all factors that can affect an individual's social and economic status, such as education, income, and occupational factors [1]. Thus, SES is thought to be closely related to health outcomes [2]. For example, socioeconomic inequality can affect mortality and morbidity, which highlights SES as an important global public health issue [3-5].

Postoperative outcomes are affected by various factors, with physiological status being one of the most important [6]. Although many studies have examined the effects of physiological factors, few studies have examined the relationship between SES and outcomes after surgery. For example, some studies have suggested that outcomes after pediatric surgery [7] or hip joint arthroplasty [8] are influenced by the patients' primary payer status. Other studies have revealed that a low SES is associated with poor cancer-specific survival among patients with colorectal cancer [9]. In addition, a more recent population-based cohort study suggested that frailty and poverty are associated with higher risks of one-year mortality after major elective noncardiac surgery [10]. Furthermore, lower SES is reportedly correlated with poor outcomes after surgery [11,12]. However, the previous studies have focused on this relationship in terms of economic and/or payer status [8-12], and it is important to be aware that this relationship may exhibit regional or national differences. 
Korea has a national health insurance system that provides patients access to treatment (including surgery), regardless of disease severity [13]. Furthermore, Korean people are known to have relatively high educational levels [14]. Therefore, it is possible that, in the Korean population, there may be a unique relationship between SES and mortality after surgery that has not been considered in previous studies. Therefore, the present study examined the associations between SES characteristics and both 30-day and one-year all-cause mortality after surgery among adults who were treated at a Korean tertiary hospital.

\section{Materials and Methods}

This study's retrospective protocol was approved by the institutional review board of the Seoul National University Bundang Hospital (SNUBH; B-1705/395-106) and adhered to the tenets of the Declaration of Helsinki. Since 2003, SNUBH has maintained an electronic medical record system, and approximately 150 surgeries are performed each day in the 38 operating rooms. Data were obtained from the medical records of patients $\geq 30$ years old who had undergone elective surgical treatment at SNUBH between 1 January 2011 and 31 December 2015. Only the last surgery was considered for patients who underwent surgery more than once during the study period. Patients were excluded if their medical records were incomplete or if they did not agree to the collection of their information at the time of admission.

\section{Data Collection and Outcomes}

Data were collected regarding the patients' demographic characteristics (sex, age, body mass index) and clinical characteristics (Charlson comorbidity index, American Society of Anesthesiologists classification, surgery type, preoperative estimated glomerular filtration rate, anesthesia type, postoperative intensive care unit admission, date of death). These data were extracted from the surgical or preanesthetic registries. In addition, patients were requested to complete an SES-related interview at their admission, although each patient had the right to refuse the release of their SES data. All data were recorded by trained nurses and maintained in the nursing records. The present study examined data regarding educational levels (less than high school, high school to less than college, college or higher), occupation (office worker, professional job [licensed job], housework, self-employed, student or military, unemployed), marital status (never married, cohabitating or married, divorced or separated, widowed), religion (Protestant, Catholic, Buddhism, others (Hinduism, Islam, Cheondogyo, none), alcohol consumption (yes, no, quit), and smoking habit (yes, never smoked, quit).

The data collection was performed by medical record technicians who were blinded to the study's purpose. The exact dates of death for patients were obtained with the approval of the Korean Ministry of the Interior and Safety. The primary outcomes for the present study were defined as the associations between preoperative SES factors and both 30-day and one-year all-cause mortality after surgery.

\section{Statistical Methods}

All data were reported as number (percent) or mean \pm standard deviation. Univariate logistic regression analyses were used to identify relationships between the patients' characteristics and 30-day or one-year mortality after surgery. Multivariable logistic regression analyses were then performed using the significant variables $(P<0.1)$ from the univariate analyses. All analyses were performed using IBM SPSS software (version 23.0; IBM Corp., Armonk, NY, USA), and differences were considered statistically significant at a $P$-value of $<0.05$.

\section{Results}

The present study evaluated data from 86,735 patients who were $\geq 30$ years old at their SNUBH admission, and a total of 108,260 surgical cases were identified. When any patient underwent two or more surgeries, only the medical record for the final surgery was included. In addition, 5766 cases were excluded because of inaccurate preoperative SES information and personal information protection. 
Thus, 80,969 patients were included in the final analysis, and their baseline characteristics are presented in Table 1. A total of 339 patients ( $0.4 \%$ ) died within 30 days after surgery, and 2687 patients (3.3\%) died within one year after surgery.

Table 1. Baseline characteristics of the total study population.

\begin{tabular}{|c|c|c|c|}
\hline \multicolumn{2}{|r|}{ Variables } & \multirow{2}{*}{$\begin{array}{c}N \text { or Value } \\
35,281 / 45,688\end{array}$} & \multirow{2}{*}{$\begin{array}{c}\text { Percent or SD } \\
43.6 \% / 56.4 \%\end{array}$} \\
\hline Gender & Male/Female & & \\
\hline & Body mass index $\left(\mathrm{kg} / \mathrm{m}^{2}\right)$ & 24.06 & 3.55 \\
\hline & Age (year) & 54.44 & 16.23 \\
\hline & Charlson comorbidity index score & 0.57 & 1.085 \\
\hline \multirow{3}{*}{ ASA Class } & I & 36,959 & $45.6 \%$ \\
\hline & II & 39,330 & $48.6 \%$ \\
\hline & $\geq \mathrm{III}$ & 4680 & $5.8 \%$ \\
\hline \multirow{9}{*}{ Type of Surgery } & Cardiovascular surgery & 1138 & $1.4 \%$ \\
\hline & General surgery & 19,474 & $24.3 \%$ \\
\hline & Neurosurgery & 2847 & $3.6 \%$ \\
\hline & Spine surgery & 4329 & $5.4 \%$ \\
\hline & Thoracic surgery & 3913 & $4.9 \%$ \\
\hline & Procedures * & 601 & $0.8 \%$ \\
\hline & Orthopedic surgery & 12,346 & $15.4 \%$ \\
\hline & ENT, Plastic, Dental, OPH & 19,514 & $24.4 \%$ \\
\hline & Urology or OBGY & 15,839 & $19.8 \%$ \\
\hline \multirow{4}{*}{$\begin{array}{l}\text { Preoperative eGFR } \\
\left(\mathrm{mL} / \mathrm{min} / 1.73 \mathrm{~m}^{2}\right)\end{array}$} & $>90$ & 50,249 & $62.1 \%$ \\
\hline & $60-90$ & 25,628 & $31.7 \%$ \\
\hline & $30-60$ & 3597 & $4.4 \%$ \\
\hline & $<30$ or RRT & 1495 & $1.8 \%$ \\
\hline \multirow{3}{*}{ Type of Anesthesia } & General anesthesia & 54,879 & $67.8 \%$ \\
\hline & Regional anesthesia & 10,644 & $13.1 \%$ \\
\hline & Monitored anesthesia care & 15,446 & $19.1 \%$ \\
\hline \multirow{2}{*}{$\begin{array}{c}\text { Postoperative ICU } \\
\text { admission }\end{array}$} & Yes & 2982 & $3.7 \%$ \\
\hline & No & 77,987 & $96.3 \%$ \\
\hline \multirow{3}{*}{ Education Level } & Less than high school & 21,191 & $26.2 \%$ \\
\hline & More than or equal to high school, less than college & 32,400 & $40.0 \%$ \\
\hline & More than, equal to college & 27,378 & $33.8 \%$ \\
\hline \multirow{6}{*}{$\begin{array}{l}\text { Occupation at } \\
\text { Surgery }\end{array}$} & Office worker & 14,874 & $18.4 \%$ \\
\hline & Professional & 4284 & $5.3 \%$ \\
\hline & Housework & 25,582 & $31.6 \%$ \\
\hline & Own business & 15,905 & $19.6 \%$ \\
\hline & Student or military & 2567 & $3.2 \%$ \\
\hline & Unemployed & 17,757 & $21.9 \%$ \\
\hline \multirow{4}{*}{ Marital Status } & Never married & 15,049 & $18.6 \%$ \\
\hline & Married, living together & 55,558 & $68.6 \%$ \\
\hline & Divorced/separated & 6459 & $8.0 \%$ \\
\hline & Widowed & 3903 & $4.8 \%$ \\
\hline \multirow{2}{*}{ Religion } & Yes & 36,017 & $44.5 \%$ \\
\hline & No & 44,952 & $55.5 \%$ \\
\hline \multirow{5}{*}{$\begin{array}{l}\text { Classification of } \\
\text { Religion }\end{array}$} & Protestantism & 16,253 & $20.1 \%$ \\
\hline & Catholicism & 7522 & $9.3 \%$ \\
\hline & Buddhism & 11,962 & $14.8 \%$ \\
\hline & Others ** & 280 & $0.3 \%$ \\
\hline & None & 44,952 & $55.5 \%$ \\
\hline \multirow{3}{*}{$\begin{array}{c}\text { Current Alcohol } \\
\text { Use }\end{array}$} & Yes & 21,277 & $26.3 \%$ \\
\hline & No & 39,138 & $48.3 \%$ \\
\hline & Quit & 20,554 & $25.4 \%$ \\
\hline \multirow{3}{*}{ Smoking History } & Yes & 17,647 & $21.8 \%$ \\
\hline & Never smoked & 42,856 & $52.9 \%$ \\
\hline & Quit & 20,466 & $25.3 \%$ \\
\hline & Current Smoker & 7582 & $9.4 \%$ \\
\hline & 30-day all-cause mortality & 339 & $0.4 \%$ \\
\hline & One-year all-cause mortality & 2687 & $3.3 \%$ \\
\hline
\end{tabular}

Procedures * Radiologic interventions or pain procedures under general anesthesia or monitored anesthetic care. Others **: Hinduism, Islam, and Cheondogyo. ASA, American Society of Anesthesiologists; ENT, Ear-Nose-Throat; $\mathrm{OPH}$, Ophthalmic; OBGY, Obstetrics and Gynecologic; eGFR, estimated Glomerular Filtration Rate; RRT, Renal Replacement Therapy; ICU, Intensive Care Unit. 


\section{30-Day and One-Year Mortality after Surgery}

The simple relationships between the patients' characteristics and 30-day mortality after surgery were analyzed using univariate logistic regression analyses (Appendix A), and significant characteristics were subsequently included in the multivariate logistic regression analyses (Table 2). Age was significantly associated with 30-day mortality after surgery (odds ratio (OR): 1.012, 95\% confidence interval (CI): 1.003-1.021, $P=0.006)$. In addition, as compared to nonreligious patients, Protestant patients had a significantly lower risk of 30-day mortality after surgery (OR: $0.642,95 \%$ CI: $0.476-0.866, P=0.004)$. As compared to never married patients, those who were married or cohabitating (OR: $0.678,95 \%$ CI: 0.462-0.995, $P=0.047$ ) and those divorced or separated (OR: 0.573, $95 \%$ CI: $0.359-0.917, P=0.02$ ) had a lower risk of 30-day mortality after surgery. Moreover, patients who consumed alcohol had an increased risk of 30-day mortality after surgery (OR: 1.390, 95\% CI: $1.048-1.844, P=0.022)$ than did patients who did not.

Table 2. Multivariate logistic regression analysis for all-cause 30-day mortality after surgery.

\begin{tabular}{|c|c|c|c|c|}
\hline \multirow{2}{*}{ Variables } & \multirow{2}{*}{ Odds Ratio } & \multicolumn{2}{|c|}{ 95\% Confidence Interval } & \multirow{2}{*}{$P$-Value } \\
\hline & & Lower Limit & Upper Limit & \\
\hline Age & 1.012 & 1.003 & 1.021 & 0.006 \\
\hline \multicolumn{5}{|l|}{ Educational Level } \\
\hline Less than high school & 1 (ref) & & & \\
\hline More than or equal to high school, less than college & 0.925 & 0.678 & 1.263 & 0.624 \\
\hline More than, equal to college & 0.925 & 0.670 & 1.277 & 0.634 \\
\hline \multicolumn{5}{|l|}{ Occupation } \\
\hline Office worker & 1 (ref) & & & \\
\hline Professional & 1.110 & 0.652 & 1.890 & 0.701 \\
\hline Housework & 0.987 & 0.693 & 1.406 & 0.943 \\
\hline Own business & 1.076 & 0.741 & 1.563 & 0.700 \\
\hline Student or military & 0.893 & 0.454 & 1.757 & 0.744 \\
\hline Unemployed & 0.880 & 0.609 & 1.272 & 0.497 \\
\hline \multicolumn{5}{|l|}{ Religion } \\
\hline None & 1 (ref) & & & \\
\hline Protestantism & 0.642 & 0.476 & 0.866 & 0.004 \\
\hline Catholicism & 0.855 & 0.565 & 1.292 & 0.456 \\
\hline Buddhism & 0.912 & 0.635 & 1.309 & 0.617 \\
\hline Others* & 55.206 & 0.000 & & 0.995 \\
\hline \multicolumn{5}{|l|}{ Marital Status } \\
\hline Never married & 1 (ref) & & & \\
\hline Married, living together & 0.678 & 0.462 & 0.995 & 0.047 \\
\hline Divorced/separated & 0.573 & 0.359 & 0.917 & 0.020 \\
\hline Widowed & 0.709 & 0.351 & 1.429 & 0.336 \\
\hline \multicolumn{5}{|l|}{ Current Alcohol Use } \\
\hline No & 1 (ref) & & & \\
\hline Yes & 1.390 & 1.048 & 1.844 & 0.022 \\
\hline Quit & 3.692 & 0.695 & 19.623 & 0.125 \\
\hline \multicolumn{5}{|l|}{ Past Smoking History } \\
\hline Yes & 1 (ref) & & & \\
\hline Never smoked & 0.872 & 0.608 & 1.251 & 0.458 \\
\hline Quit & 0.252 & 0.047 & 1.341 & 0.106 \\
\hline Current Smoking (Yes) & 1.344 & 0.882 & 2.047 & 0.168 \\
\hline
\end{tabular}

Hosmer-Lemeshow Stats $=8.825(P=0.357)$. Others *: Hinduism, Islam, and Cheondogyo.

The simple relationships between the patients' characteristics and one-year mortality after surgery were analyzed using univariate logistic regression analyses (Appendix B), and Table 3 shows the results of the multivariate logistic regression analyses for one-year mortality after surgery. Among the SES characteristics, only being married or cohabitating was associated with a decreased risk of one-year mortality after surgery (OR: $0.857,95 \%$ CI: $0.746-0.983, P=0.028$ ). The Hosmer-Lemeshow test results were appropriate $(P>0.05)$. 
Table 3. Multivariate logistic regression analysis for all-cause one-year mortality after surgery.

\begin{tabular}{|c|c|c|c|c|}
\hline & \multirow{2}{*}{ Odds Ratio } & \multicolumn{2}{|c|}{ 95\% Confidence Interval } & \multirow{2}{*}{$P$-Value } \\
\hline & & Lower Limit & Upper Limit & \\
\hline Age (year) & 1.001 & 0.998 & 1.004 & 0.570 \\
\hline \multicolumn{5}{|l|}{ Preoperative eGFR $\left(\mathrm{mL} / \mathrm{min} / 1.73 \mathrm{~m}^{2}\right)$} \\
\hline$>90$ & 1 (ref) & & & \\
\hline $60-90$ & 1.162 & 1.061 & 1.273 & $<0.001$ \\
\hline $30-60$ & 1.373 & 1.098 & 1.717 & 0.005 \\
\hline$<30$ or RRT & 1.033 & 0.758 & 1.409 & 0.835 \\
\hline \multicolumn{5}{|l|}{ ASA Class } \\
\hline I & 1 (ref) & & & \\
\hline II & 0.970 & 0.887 & 1.062 & 0.515 \\
\hline III, IV, V & 1.153 & 0.940 & 1.415 & 0.171 \\
\hline \multicolumn{5}{|l|}{ Educational Level } \\
\hline Less than high school & 1 (ref) & & & \\
\hline More than or equal to high school, Less than college & 0.932 & 0.834 & 1.041 & 0.217 \\
\hline More than, equal to college & 0.909 & 0.807 & 1.022 & 0.111 \\
\hline \multicolumn{5}{|l|}{ Occupation } \\
\hline Office worker & 1 (ref) & & & \\
\hline Professional & 1.124 & 0.923 & 1.369 & 0.246 \\
\hline Housework & 1.059 & 0.926 & 1.195 & 0.402 \\
\hline Own business & 1.127 & 0.993 & 1.295 & 0.081 \\
\hline Student or military & 0.790 & 0.617 & 1.003 & 0.064 \\
\hline Unemployed & 1.013 & 0.883 & 1.162 & 0.853 \\
\hline \multicolumn{5}{|l|}{ Religion } \\
\hline None & 1 (ref) & & & \\
\hline Protestantism & 0.962 & 0.859 & 1.078 & 0.508 \\
\hline Catholicism & 0.948 & 0.819 & 1.097 & 0.473 \\
\hline Buddhism & 0.983 & 0.866 & 1.115 & 0.787 \\
\hline Others * & 2.265 & 0.841 & 6.099 & 0.106 \\
\hline \multicolumn{5}{|l|}{ Marital Status } \\
\hline Never married & 1 (ref) & & & \\
\hline Married, living together & 0.857 & 0.746 & 0.983 & 0.028 \\
\hline Divorced/separated & 0.884 & 0.741 & 1.054 & 0.170 \\
\hline Widowed & 0.883 & 0.692 & 1.126 & 0.316 \\
\hline \multicolumn{5}{|l|}{ Current Alcohol Use } \\
\hline No & 1 (ref) & & & \\
\hline Yes & 1.073 & 0.964 & 1.194 & 0.199 \\
\hline Quit & 1.331 & 0.646 & 2.740 & 0.438 \\
\hline \multicolumn{5}{|l|}{ Past Smoking History } \\
\hline Yes & 1 (ref) & & & \\
\hline Never smoked & 0.954 & 0.834 & 1.092 & 0.495 \\
\hline Quit & 0.739 & 0.356 & 1.533 & 0.417 \\
\hline Current Smoking: No & 0.923 & 0.781 & 1.091 & 0.347 \\
\hline
\end{tabular}

Hosmer-Lemeshow stat $=2.669(P=0.953)$. Others *: Hinduism, Islam, and Cheondogyo. eGFR, estimated Glomerular Filtration Rate; RRT, Renal Replacement Therapy; ASA, American Society of Anesthesiologists.

\section{Discussion}

The present study demonstrated that several SES characteristics were significantly associated with 30-day and one-year all-cause mortality after surgery. For example, reduced risks of 30-day mortality after surgery were observed among patients who were Protestants (vs. nonreligious), married or cohabitating (vs. never married), divorced or separated (vs. never married), and those who did not consume alcohol (vs. patients who did). However, a reduced risk of one-year mortality after surgery was only observed among patients who were married or cohabitating (vs. never married patients). None of the other variables, such as educational level or occupation, were associated with 30-day or one-year all-cause mortality. Our study is valuable, in that all Korean patients are covered by the national health insurance system, regardless of their income. Therefore, there was equal access for 
Korean patients to tertiary care hospitals in receiving surgical procedures regardless of the preoperative SES factors.

Marital status has been reported to improve mortality after surgery in cases that involve radical cystectomy [15] or elective colectomy [16], but not in cases that involve esophagectomy [17]. However, those studies are limited by their focus on specific diseases. In contrast, the present study only included adult patients ( $\geq 30$ years old) who underwent surgery at a tertiary hospital during a five-year period, which provides a broader evaluation of the relationship between SES and mortality after surgery. The present study revealed that never-married patients were at increased risk of 30-day and one-year all-cause mortality after surgery. Interestingly, a recent study evaluated the association between marital status and mortality after noncardiac surgery among 11,588 American patients and revealed a $31 \%$ higher risk of mortality among male unmarried patients [18]. In contrast, we did not detect a significant difference in mortality risk when we compared men and women according to their marital status.

The improved outcomes among married patients may be attributed to the psychological, economic, and social benefits of marriage $[19,20]$. In addition, given the relationship between marital status and 30-day mortality (which is similar to in-hospital mortality), social and psychological support appear to affect both everyday situations and needs during hospital stays. Furthermore, emotional support is a strong independent predictor of prognosis among elderly patients who are hospitalized because of heart failure [21]. Thus, the positive effects of being married on 30-day mortality are understandable. Nevertheless, it is intriguing that the same benefit was observed among divorced or separated patients (vs. the never-married group), and further studies are needed to examine this issue, as divorce is generally thought to be related to negative health outcomes [22]. It is possible that divorced or separated patients receive emotional and psychological support from their children, which might be related to better support and less stress, whereas never-married patients may not receive equivalent support.

The present study revealed that Protestant patients had a decreased risk of 30-day mortality after surgery, as compared to nonreligious patients, which may be related to emotional support. In this context, Protestantism is the most popular and vibrant religion in Korea [23], and the weekly worship services at SNUBH are attended by a large number of patients and caregivers. A previous meta-analysis also suggested that religious involvement reduces mortality [24], which supports our findings that Protestantism was associated with a decreased risk of 30-day mortality after surgery.

Another interesting finding was that current alcohol use, but not smoking status, influenced the risk of mortality after surgery. In Korea, alcohol consumption is associated with increased risks of mortality, including cancer-related mortality [25]. Although smoking is also a known risk factor for mortality [26], its effects are not typically observed during relatively short follow-up periods (e.g., the 30-day and one-year periods that we studied). Furthermore, it is recommended that patients who undergo surgery with anesthesia at SNUBH stop smoking, given the risks that are associated with smoking in this setting [27]. Thus, this policy might have eliminated any effect of smoking on 30-day mortality.

Lastly, an interesting fact concerning our study is that, preoperative American Society of Anesthesiologists (ASA) classification and Charlson comorbidity index scores were not associated with 30-day and 1-year mortality after surgery. ASA classification and Charlson-related comorbidity are known important risk factors of mortality after surgery [28,29]. To some extent, it might be explained that, our study included all patients, regardless of the duration or risk of operation among non-cardiovascular surgeries. In general, previous studies were performed for specific surgeries or populations to explain the impact of the preoperative comorbidities of patients [28-30]. Our study aimed to know the impact of preoperative SES factors on the outcome after surgery, thus, the inclusion of the general population might have reduced the effect of the physical comorbidity in our study. However, further study is needed to show the effect of preoperative SES factor in addition to preoperative comorbidities. 
The present study has several limitations. First, the retrospective design is associated with a known risk of bias. Second, data were only obtained from a single tertiary hospital in South Korea, and the results may not be generalized to broader and more diverse patient populations in other countries. Third, we were unable to obtain accurate causes of death for all patients; therefore, we could only analyze all-cause 30 day and one-year mortality, rather than disease-specific mortality. Furthermore, it is possible that all-cause one-year mortality after surgery is less likely to be due to the procedure itself and much more likely to be due to age and co-existing disease. Fourth, income data of patients were not collected and could not be included in the analyses. Lastly, our study did not analyze specific procedure-related and comorbidity-related variables such as the length of surgical procedures, risk classification, estimated blood loss, and serious cardiac and pulmonary comorbidities. Therefore, it is possible that the significant findings may be due to unknown associations with other unaccounted for variables. Nevertheless, the present study provides valuable information regarding the associations between SES characteristics and both 30-day and one-year mortality after surgery among Korean patients who underwent both cardiac and noncardiac surgery.

\section{Conclusions}

In conclusion, we found that the never-married status was associated with increased risks of 30-day and one-year all-cause mortality after surgery among Korean patients $\geq 30$ years old, as compared to patients who were married or cohabitating. In addition, as compared to nonreligious patients, Protestant patients had a decreased risk of 30-day all-cause mortality after surgery.

Author Contributions: T.K.O. designed the study, analyzed the data, and drafted the manuscript; K.N.K., S.H.D., J.W.H. and Y.T.J. contributed to the acquisition of data; all authors gave approval for the final version of the manuscript.

Conflicts of Interest: The authors declare no conflicts of interest.

\section{Appendix A}

Table A1. Univariate logistic regression analysis for all-cause 30-day mortality after surgery.

\begin{tabular}{ccccc}
\hline Variable & \multirow{2}{*}{ Odds Ratio } & \multicolumn{2}{c}{$\mathbf{9 5 \% \text { Confidence Interval }}$} & \multirow{2}{*}{$\boldsymbol{P}$-Value } \\
\cline { 3 - 4 } & & Lower Limit & Upper Limit & \\
\hline Gender: female & 0.980 & 0.790 & 1.215 & 0.851 \\
Body mass index $\left(\mathrm{kg} / \mathrm{m}^{2}\right)$ & 1.008 & 0.978 & 1.038 & 0.627 \\
Age (year) & 1.009 & 1.003 & 1.016 & 0.006 \\
\hline Type of surgery & & & & \\
Cardiovascular surgery & $1(\mathrm{ref})$ & & & \\
General surgery & 1.580 & 0.727 & 3.434 & 0.248 \\
Neurosurgery & 1.349 & 0.537 & 3.390 & 0.524 \\
Spine Surgery & 1.570 & 0.649 & 3.795 & 0.317 \\
Thoracic Surgery & 2.195 & 0.849 & 5.677 & 0.105 \\
Procedures * & 3.714 & 0.456 & 30.253 & 0.220 \\
Orthopedic surgery & 1.311 & 0.597 & 2.879 & 0.500 \\
ENT, Plastic, Dental, Eye surgery & 1.485 & 0.684 & 3.221 & 0.317 \\
Urologic or OBGY surgery & 1.394 & 0.640 & 3.039 & 0.403 \\
\hline Preoperative eGFR (mL/min/1.73 $\left.\mathrm{m}^{2}\right)$ & & & & \\
>90 & 1 (ref) & & & \\
$90-60$ & 1.186 & 0.933 & 1.507 & 0.164 \\
60-30 & 1.141 & 0.664 & 1.960 & 0.633 \\
<30 or RRT & 1.106 & 0.491 & 2.493 & 0.808 \\
\hline ASA Class & & & & \\
I & 1 (ref) & & & \\
II & 1.231 & 0.987 & 1.534 & 0.065 \\
III, IV, V & 1.083 & 0.681 & 1.723 & 0.736 \\
\hline Charlson Comorbidity Index Score & 0.995 & 0.903 & 1.097 & 0.919 \\
\hline
\end{tabular}


Table A1. Cont.

\begin{tabular}{|c|c|c|c|c|}
\hline \multirow{2}{*}{ Variable } & \multirow{2}{*}{ Odds Ratio } & \multicolumn{2}{|c|}{ 95\% Confidence Interval } & \multirow{2}{*}{$P$-Value } \\
\hline & & Lower Limit & Upper Limit & \\
\hline \multicolumn{5}{|l|}{ Type of Anesthesia } \\
\hline General anesthesia & 1 (ref) & & & \\
\hline Regional anesthesia & 0.751 & 0.561 & 1.006 & 0.055 \\
\hline Monitored anesthesia care & 1.018 & 0.766 & 1.352 & 0.903 \\
\hline Postoperative ICU admission & 1.297 & 0.784 & 2.146 & 0.311 \\
\hline \multicolumn{5}{|l|}{ Educational level } \\
\hline Less than high school & 1 (ref) & & & \\
\hline More than or equal to high school, less than college & 0.876 & 0.663 & 1.158 & 0.354 \\
\hline More than, equal to college & 0.805 & 0.607 & 1.069 & 0.135 \\
\hline \multicolumn{5}{|l|}{ Occupation } \\
\hline Office Worker & 1 (ref) & & & \\
\hline Professional & 1.040 & 0.617 & 1.755 & 0.882 \\
\hline Housework & 1.065 & 0.781 & 1.452 & 0.691 \\
\hline Own business & 1.104 & 0.780 & 1.562 & 0.578 \\
\hline Student or military & 0.862 & 0.475 & 1.566 & 0.627 \\
\hline Unemployed & 1.035 & 0.742 & 1.444 & 0.840 \\
\hline Religion: No (vs. Yes) & 1.170 & 0.945 & 1.449 & 0.149 \\
\hline Protestantism & 1 & & & \\
\hline Catholicism & 1.315 & 0.873 & 1.983 & 0.190 \\
\hline Buddhism & 1.442 & 0.006 & 2.066 & 0.056 \\
\hline Others ** & & 0.000 & & 0.995 \\
\hline None & 1.393 & 0.077 & 1.801 & 0.051 \\
\hline \multicolumn{5}{|l|}{ Marriage Status } \\
\hline Single & 1 (ref) & & & \\
\hline Married, living together & 0.818 & 0.607 & 1.102 & 0.187 \\
\hline Divorced/separated & 0.668 & 0.434 & 1.028 & 0.067 \\
\hline Widowed & 1.058 & 0.576 & 1.942 & 0.857 \\
\hline \multicolumn{5}{|l|}{ Current Alcohol Use } \\
\hline Yes & 1 (ref) & & & \\
\hline No & 0.008 & 1.401 & 1.094 & 1 \\
\hline Quit & 0.065 & 1.309 & 0.984 & 1 \\
\hline \multicolumn{5}{|l|}{ Past Smoking History } \\
\hline Yes & 1 (ref) & & & \\
\hline No & 1.125 & 0.864 & 1.464 & 0.383 \\
\hline Quit & 1.132 & 0.833 & 1.539 & 0.427 \\
\hline Current Smoking: No & 1.371 & 0.991 & 1.895 & 0.056 \\
\hline
\end{tabular}

Procedures *: Radiologic interventions or pain procedures under general anesthesia or monitored anesthetic care. Others **: Hinduism, Islam, and Cheondogyo. ENT, Ear Nose and Throat; OBGY, Obstetrics and gynecologic; eGFR, estimated glomerular filtration rate; ASA, American Society of Anesthesiologists; ICU, Intensive care unit; RRT, renal replacement therapy.

\section{Appendix B}

Table A2. Univariate logistic regression analysis for all-cause one-year mortality after surgery.

\begin{tabular}{|c|c|c|c|c|}
\hline \multirow{2}{*}{ Variable } & \multirow{2}{*}{ Odds Ratio } & \multicolumn{2}{|c|}{ 95\% Confidence Interval } & \multirow{2}{*}{$P$-Value } \\
\hline & & Lower Limit & Upper Limit & \\
\hline Gender: female & 0.983 & 0.910 & 1.063 & 0.669 \\
\hline Body mass index $\left(\mathrm{kg} / \mathrm{m}^{2}\right)$ & 1.007 & 0.997 & 1.018 & 0.182 \\
\hline Age (year) & 1.003 & 1.001 & 1.006 & 0.005 \\
\hline \multicolumn{5}{|l|}{ Type of surgery } \\
\hline Cardiovascular surgery & 1 & & & \\
\hline General surgery & 0.905 & 0.640 & 1.278 & 0.569 \\
\hline Neurosurgery & 1.142 & 0.761 & 1.713 & 0.522 \\
\hline Spine Surgery & 0.942 & 0.647 & 1.373 & 0.758 \\
\hline Thoracic Surgery & 0.986 & 0.673 & 1.444 & 0.942 \\
\hline Procedures * & 0.876 & 0.506 & 1.519 & 0.638 \\
\hline Orthopedic surgery & 0.945 & 0.665 & 1.343 & 0.753 \\
\hline ENT, Plastic, Dental, Eye surgery & 0.917 & 0.649 & 1.295 & 0.621 \\
\hline Urologic or OBGY surgery & 0.909 & 0.643 & 1.287 & 0.592 \\
\hline
\end{tabular}


Table A2. Cont.

\begin{tabular}{|c|c|c|c|c|}
\hline \multirow{2}{*}{ Variable } & \multirow{2}{*}{ Odds Ratio } & \multicolumn{2}{|c|}{ 95\% Confidence Interval } & \multirow{2}{*}{$P$-Value } \\
\hline & & Lower Limit & Upper Limit & \\
\hline \multicolumn{5}{|l|}{ Preoperative eGFR $\left(\mathrm{mL} / \mathrm{min} / 1.73 \mathrm{~m}^{2}\right)$} \\
\hline$>90$ & 1 & & & \\
\hline $90-60$ & 1.168 & 1.072 & 1.272 & $<0.001$ \\
\hline 60-30 & 1.424 & 1.149 & 1.765 & 0.001 \\
\hline$<30$ or RRT & 1.126 & 0.839 & 1.512 & 0.429 \\
\hline \multicolumn{5}{|l|}{ ASA Class } \\
\hline I & 1 & & & \\
\hline II & 1.028 & 0.950 & 1.113 & 0.487 \\
\hline III, IV, V & 1.252 & 1.041 & 1.506 & 0.017 \\
\hline Charlson Comorbidity Index Score & 1.019 & 0.982 & 1.056 & 0.317 \\
\hline \multicolumn{5}{|l|}{ Type of anesthesia } \\
\hline General anesthesia & 1 & & & \\
\hline Regional anesthesia & 0.981 & 0.874 & 1.100 & 0.738 \\
\hline Monitored anesthesia care & 0.984 & 0.890 & 1.086 & 0.743 \\
\hline Postoperative ICU admission & 1.011 & 0.825 & 1.239 & 0.914 \\
\hline \multicolumn{5}{|l|}{ Educational level } \\
\hline Less than high school & 1 & & & \\
\hline More than or equal to high school, less than college & 0.935 & 0.847 & 1.031 & 0.178 \\
\hline More than, equal to college & 0.899 & 0.812 & 0.994 & 0.038 \\
\hline \multicolumn{5}{|l|}{ Occupation } \\
\hline Office worker & 1 & & & \\
\hline Professional & 1.107 & 0.914 & 1.341 & 0.299 \\
\hline Housework & 1.052 & 0.942 & 1.176 & 0.367 \\
\hline Own business & 1.142 & 1.007 & 1.295 & 0.038 \\
\hline Student or military & 0.835 & 0.675 & 1.032 & 0.095 \\
\hline Unemployed & 1.075 & 0.953 & 1.213 & 0.239 \\
\hline Religion: No (vs. Yes) & 1.012 & 0.937 & 1.094 & 0.759 \\
\hline Protestantism & 1 & & & \\
\hline Catholicism & 0.982 & 0.845 & 1.140 & 0.809 \\
\hline Buddhism & 1.064 & 0.932 & 1.215 & 0.358 \\
\hline Others ** & 2.435 & 0.904 & 6.557 & 0.078 \\
\hline None & 1.034 & 0.936 & 1.142 & 0.513 \\
\hline \multicolumn{5}{|l|}{ Marriage status } \\
\hline Single & 1 & & & \\
\hline Married, living together & 0.972 & 0.878 & 1.075 & 0.576 \\
\hline Divorced/separated & 0.979 & 0.832 & 1.153 & 0.803 \\
\hline Widowed & 1.091 & 0.889 & 1.339 & 0.403 \\
\hline \multicolumn{5}{|l|}{ Current alcohol use } \\
\hline Yes & 1 & & & \\
\hline No & 0.949 & 0.859 & 1.048 & 0.299 \\
\hline Quit & 0.958 & 0.855 & 1.073 & 0.455 \\
\hline \multicolumn{5}{|l|}{ Past Smoking History } \\
\hline Yes & 1 & & & \\
\hline No & 0.949 & 0.859 & 1.048 & 0.299 \\
\hline Quit & 0.958 & 0.855 & 1.073 & 0.455 \\
\hline Current Smoking: No & 0.921 & 0.804 & 1.055 & 0.236 \\
\hline
\end{tabular}

Procedures *: Radiologic interventions or pain procedures under general anesthesia or monitored anesthetic care. Others **: Hinduism, Islam, and Cheondogyo. ENT, Ear Nose and Throat; OBGY, Obstetrics and gynecologic; eGFR, estimated glomerular filtration rate; ASA, American Society of Anesthesiologists; ICU, Intensive care unit; RRT, renal replacement therapy.

\section{References}

1. Baker, E.H. Socioeconomic status, definition. In The Wiley Blackwell Encyclopedia of Health, Illness, Behavior, and Society; Wiley-Blackwell: Chichester, UK, 2014; pp. 2210-2214.

2. Kennedy, B.P.; Kawachi, I.; Glass, R.; Prothrow-Stith, D. Income distribution, socioeconomic status, and self rated health in the United States: Multilevel analysis. BMJ 1998, 317, 917-921. [CrossRef] [PubMed]

3. Mackenbach, J.P.; Kunst, A.E.; Cavelaars, A.E.; Groenhof, F.; Geurts, J.J.; EU working group on socioeconomic inequalities in health. Socioeconomic inequalities in morbidity and mortality in Western Europe. Lancet 1997, 349, 1655-1659. [CrossRef] 
4. $\quad$ Lantz, P.M.; House, J.S.; Lepkowski, J.M.; Williams, D.R.; Mero, R.P.; Chen, J. Socioeconomic factors, health behaviors, and mortality: Results from a nationally representative prospective study of US adults. JAMA 1998, 279, 1703-1708. [CrossRef] [PubMed]

5. Marmot, M. Social determinants of health inequalities. Lancet 2005, 365, 1099-1104. [CrossRef]

6. Wolters, U.; Wolf, T.; Stutzer, H.; Schroder, T. ASA classification and perioperative variables as predictors of postoperative outcome. Br. J. Anaesth. 1996, 77, 217-222. [CrossRef] [PubMed]

7. Stone, M.L.; LaPar, D.J.; Mulloy, D.P.; Rasmussen, S.K.; Kane, B.J.; McGahren, E.D.; Rodgers, B.M. Primary payer status is significantly associated with postoperative mortality, morbidity, and hospital resource utilization in pediatric surgical patients within the United States. J. Pediatr. Surg. 2013, 48, 81-87. [CrossRef] [PubMed]

8. Bozic, K.J.; Lau, E.; Kurtz, S.; Ong, K.; Rubash, H.; Vail, T.P.; Berry, D.J. Patient-related risk factors for periprosthetic joint infection and postoperative mortality following total hip arthroplasty in medicare patients. J. Bone Jt. Surg. Am. 2012, 94, 794-800. [CrossRef] [PubMed]

9. Hole, D.J.; McArdle, C.S. Impact of socioeconomic deprivation on outcome after surgery for colorectal cancer. Br. J. Surg. 2002, 89, 586-590. [CrossRef] [PubMed]

10. McIsaac, D.I.; Bryson, G.L.; van Walraven, C. Association of frailty and 1-year postoperative mortality following major elective noncardiac surgery: A population-based cohort study. JAMA Surg. 2016, 151, 538-545. [CrossRef] [PubMed]

11. Ambur, V.; Taghavi, S.; Kadakia, S.; Jayarajan, S.; Gaughan, J.; Sjoholm, L.O.; Pathak, A.; Santora, T.; Rappold, J.; Goldberg, A.J. Does socioeconomic status predict outcomes after cholecystectomy? Am. J. Surg. 2017, 213, 100-104. [CrossRef] [PubMed]

12. Van Roest, M.H.; van der Aa, M.A.; van der Geest, L.G.; de Jong, K.P. The impact of socioeconomic status, surgical resection and type of hospital on survival in patients with pancreatic cancer. A population-based study in the Netherlands. PLoS ONE 2016, 11, e0166449. [CrossRef] [PubMed]

13. Lim, B. Korean medicine coverage in the national health insurance in Korea: Present situation and critical issues. Integr. Med. Res. 2013, 2, 81-88. [CrossRef] [PubMed]

14. Anderson, T.; Kohler, H.P. Education fever and the east Asian fertility puzzle: A case study of low fertility in South Korea. Asian Popul. Stud. 2013, 9, 196-215. [CrossRef] [PubMed]

15. Schiffmann, J.; Gandaglia, G.; Larcher, A.; Sun, M.; Tian, Z.; Shariat, S.F.; McCormack, M.; Valiquette, L.; Montorsi, F.; Graefen, M.; et al. Contemporary 90-day mortality rates after radical cystectomy in the elderly. Eur. J. Surg. Oncol. 2014, 40, 1738-1745. [CrossRef] [PubMed]

16. Neuman, H.B.; Weiss, J.M.; Leverson, G.; O'Connor, E.S.; Greenblatt, D.Y.; Loconte, N.K.; Greenberg, C.C.; Smith, M.A. Predictors of short-term postoperative survival after elective colectomy in colon cancer patients $>/=80$ years of age. Ann. Surg. Oncol. 2013, 20, 1427-1435. [CrossRef] [PubMed]

17. Ra, J.; Paulson, E.C.; Kucharczuk, J.; Armstrong, K.; Wirtalla, C.; Rapaport-Kelz, R.; Kaiser, L.R.; Spitz, F.R. Postoperative mortality after esophagectomy for cancer: Development of a preoperative risk prediction model. Ann. Surg. Oncol. 2008, 15, 1577-1584. [CrossRef] [PubMed]

18. Gulack, B.C.; Hale, B.; White, W.D.; Moon, R.E.; Bennett-Guerrero, E. Marriage and mortality after noncardiac surgery. J. Surg. Res. 2017, 210, 152-158. [CrossRef] [PubMed]

19. Smock, P.J.; Manning, W.D.; Gupta, S. The effect of marriage and divorce on women's economic well-being. Am. Sociol. Rev. 1999, 794-812. [CrossRef]

20. Wight, R.G.; Leblanc, A.J.; Lee Badgett, M.V. Same-sex legal marriage and psychological well-being: Findings from the California health interview survey. Am. J. Public Health 2013, 103, 339-346. [CrossRef] [PubMed]

21. Krumholz, H.M.; Butler, J.; Miller, J.; Vaccarino, V.; Williams, C.S.; Mendes de Leon, C.F.; Seeman, T.E.; Kasl, S.V.; Berkman, L.F. Prognostic importance of emotional support for elderly patients hospitalized with heart failure. Circulation 1998, 97, 958-964. [CrossRef] [PubMed]

22. Sbarra, D.A.; Coan, J.A. Divorce and health: Good data in need of better theory. Curr. Opin. Psychol. 2017, 13, 91-95. [CrossRef] [PubMed]

23. Kim, A.E. Korean religious culture and its affinity to Christianity: The rise of protestant Christianity in South Korea. Sociol. Relig. 2000, 61, 117-133. [CrossRef]

24. McCullough, M.E.; Hoyt, W.T.; Larson, D.B.; Koenig, H.G.; Thoresen, C. Religious involvement and mortality: A meta-analytic review. Health Psychol. 2000, 19, 211-222. [CrossRef] [PubMed] 
25. Kim, M.K.; Ko, M.J.; Han, J.T. Alcohol consumption and mortality from all-cause and cancers among 1.34 million Koreans: The results from the Korea national health insurance corporation's health examinee cohort in 2000. Cancer Causes Control. 2010, 21, 2295-2302. [CrossRef] [PubMed]

26. Jee, S.H.; Lee, J.K.; Kim, I.S. Smoking-attributable mortality among Korean adults: 1981-2003. Korean J. Epidemiol. 2006, 28, 92-99.

27. Bluman, L.G.; Mosca, L.; Newman, N.; Simon, D.G. Preoperative smoking habits and postoperative pulmonary complications. Chest 1998, 113, 883-889. [CrossRef] [PubMed]

28. Fu, K.M.; Smith, J.S.; Polly, D.W., Jr.; Ames, C.P.; Berven, S.H.; Perra, J.H.; McCarthy, R.E.; Knapp, D.R., Jr.; Shaffrey, C.I.; Scoliosis Research Society, M.; et al. Correlation of higher preoperative American society of anesthesiology grade and increased morbidity and mortality rates in patients undergoing spine surgery. J. Neurosurg. Spine 2011, 14, 470-474. [CrossRef] [PubMed]

29. Ouellette, J.R.; Small, D.G.; Termuhlen, P.M. Evaluation of Charlson-Age Comorbidity index as predictor of morbidity and mortality in patients with colorectal carcinoma. J. Gastrointest. Surg. 2004, 8, 1061-1067. [CrossRef] [PubMed]

30. Froehner, M.; Koch, R.; Litz, R.; Heller, A.; Oehlschlaeger, S.; Wirth, M.P. Comparison of the American society of anesthesiologists physical status classification with the Charlson score as predictors of survival after radical prostatectomy. Urology 2003, 62, 698-701. [CrossRef]

(c) 2018 by the authors. Licensee MDPI, Basel, Switzerland. This article is an open access article distributed under the terms and conditions of the Creative Commons Attribution (CC BY) license (http://creativecommons.org/licenses/by/4.0/). 